\title{
Review Article \\ The Role of Tissue Macrophage-Mediated Inflammation on NAFLD Pathogenesis and Its Clinical Implications
}

\author{
Anna Alisi, ${ }^{1}$ Guido Carpino, ${ }^{2}$ Felipe L. Oliveira, ${ }^{3}$ \\ Nadia Panera, ${ }^{1}$ Valerio Nobili, ${ }^{4}$ and Eugenio Gaudio ${ }^{5}$ \\ ${ }^{1}$ Liver Research Unit of Bambino Gesù Children's Hospital and IRCCS, Rome, Italy \\ ${ }^{2}$ Department of Movement, Human and Health Sciences, Division of Health Sciences, University of Rome "Foro Italico", Rome, Italy \\ ${ }^{3} \mathrm{Federal}$ University of Rio de Janeiro, Institute of Biomedical Sciences, Rio de Janeiro, Brazil \\ ${ }^{4}$ Hepato-Metabolic Disease Unit of Bambino Gesù Children's Hospital and IRCCS, Rome, Italy \\ ${ }^{5}$ Department of Anatomical, Histological, Forensic Medicine and Orthopedics Sciences, Sapienza University of Rome, Rome, Italy
}

Correspondence should be addressed to Valerio Nobili; vnobili66@gmail.com

Received 26 September 2016; Revised 22 November 2016; Accepted 4 December 2016; Published 1 January 2017

Academic Editor: Dah-Yuu Lu

Copyright (C) 2017 Anna Alisi et al. This is an open access article distributed under the Creative Commons Attribution License, which permits unrestricted use, distribution, and reproduction in any medium, provided the original work is properly cited.

\begin{abstract}
The obese phenotype is characterized by a state of chronic low-grade systemic inflammation that contributes to the development of comorbidities, including nonalcoholic fatty liver disease (NAFLD). In fact, NAFLD is often associated with adipocyte enlargement and consequent macrophage recruitment and inflammation. Macrophage polarization is often associated with the proinflammatory state in adipose tissue. In particular, an increase of M1 macrophages number or of M1/M2 ratio triggers the production and secretion of various proinflammatory signals (i.e., adipocytokines). Next, these inflammatory factors may reach the liver leading to local M1/M2 macrophage polarization and consequent onset of the histological damage characteristic of NAFLD. Thus, the role of macrophage polarization and inflammatory signals appears to be central for pathogenesis and progression of NAFLD, even if the heterogeneity of macrophages and molecular mechanisms that govern their phenotype switch remain incompletely understood. In this review, we discuss the role of adipose and liver tissue macrophage-mediated inflammation in experimental and human NAFLD. This focus is relevant because it may help researchers that approach clinical and experimental studies on this disease advancing the knowledge of mechanisms that could be targeted in order to revert NAFLD-related fibrosis.
\end{abstract}

\section{Introduction}

Nonalcoholic fatty liver disease (NAFLD) comprises more than one hepatic spectrum. It is a benign condition characterized by simple intrahepatic triglyceride accumulation (i.e., steatosis), which in turn may progress to a more severe form exhibiting steatosis, hepatocellular damage (i.e., ballooning), and tissue inflammation, collectively known as nonalcoholic steatohepatitis (NASH) [1]. However, this old paradigm has been challenged by several studies suggesting that patients with simple steatosis might not constitute a homogenous population. While some of these patients may progress unequivocally towards NASH, others may develop fibrosis directly, bypassing NASH as intermediate step [2].

Currently considered the most common liver disease worldwide, NAFLD is characterized by a rising prevalence in all age groups $[3,4]$. It is widely accepted that the increased prevalence of NAFLD is strongly associated with the increasing prevalence of obesity. Development and progression of NAFLD are the result of a complex interplay between different organs and cell types. Indeed, the expansion of visceral adipose tissue and gut-derived endotoxins are key factors in NAFLD and its progression to fibrosis [5-10].

During obesity, adipocyte size may dramatically increase. This hypertrophy promotes the rupture of adipocytes leading to a local inflammatory phenotype marked by the recruitment and activation of immune cells, such as macrophages and $\mathrm{T}$ cells, and by production of adipose tissue proinflammatory molecules (i.e., adipocytokines) that are released into circulation and can reach target organs, including the liver and skeletal muscle [5]. This aberrant activation of the immune response triggers harmful inflammation, which 


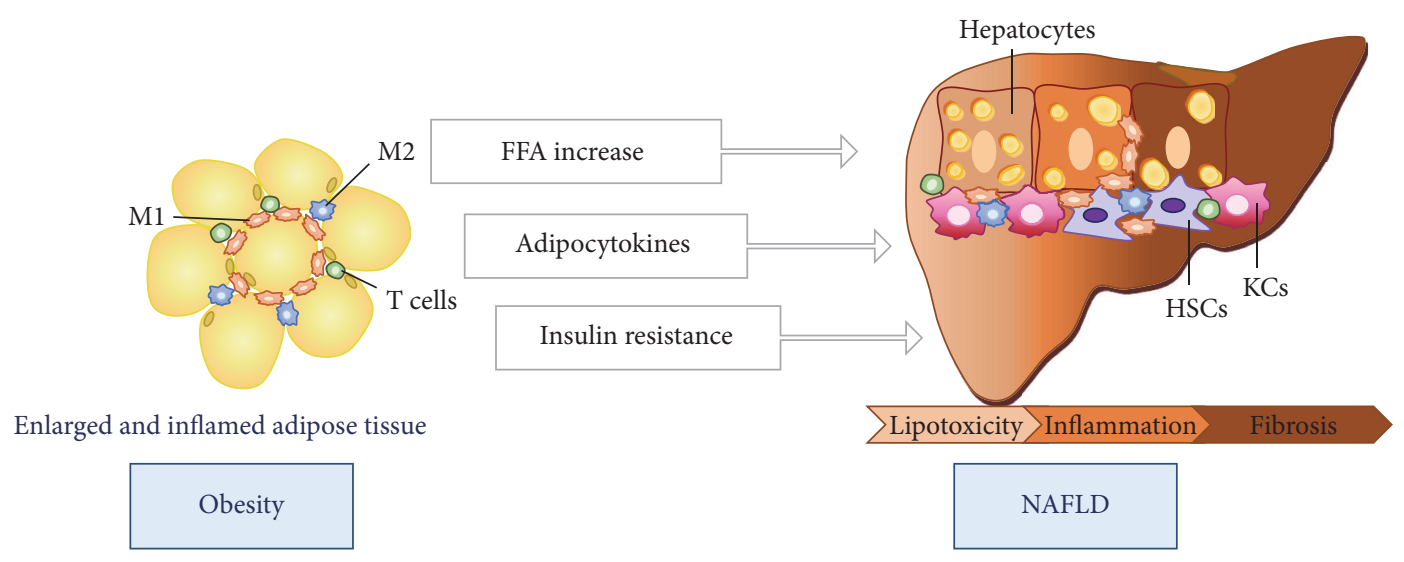

FIGURE 1: The crosstalk between adipose tissue macrophages and the liver cells in NAFLD.

impairs the ability of insulin to inhibit free fatty acids (FFA) release causing their accumulation in the liver and consequent lipotoxicity, induces hepatic insulin resistance, and drives the low-grade inflammatory pattern of NASH and, later, liver fibrosis (Figure 1) [6].

Gut is now emerging as initiator of the events that contribute to obesity-associated systemic inflammation [7]. More specifically, obesity prone subjects exhibit alterations in gut microbiota balance (i.e., dysbiosis). A major compound of gut bacteria, lipopolysaccharide (LPS), plays a key role in hepatic inflammation and in macrophage polarization during NAFLD. Clinical evidence demonstrates that, in NAFLD subjects, LPS does not remain confined in the intestinal lumen but reaches the liver when the colonic mucosa immune function is impaired by gut dysbiosis $[8,9]$. Toll-like receptor 4 (TLR-4) on the plasma membrane of liver-resident cells recognizes LPS as a ligand that prompts receptor dimerization and consequent activation of a signalling cascade. Next, the LPS/TLR-4 cascade causes the production of classical inflammatory cytokines, including tumour necrosis factor(TNF-) $\alpha$, interleukin- (IL-) $1 \beta$, and IL-6, exacerbating the hepatic inflammatory state and promoting fibrogenesis [10].

Despite what triggers the obesity-dependent proinflammatory response, advances in obesity research have led to the recognition of a primary role of the immune cells, such as macrophages and T-lymphocytes, in metabolic tissues. In particular, the crosstalk between tissue resident macrophages and adipocytes or hepatocytes appears to be for NAFLD development and progression. Therefore, macrophage-driven inflammation in NAFLD pathogenesis involves two different primary components that should be considered: one occurring in the adipose tissue and the other in the liver [11]. The identification of the pivotal molecules associated with the dynamic changes of macrophages and understanding their interactions could be crucial for designing novel therapeutic approaches against NAFLD.

Here, we review the role of macrophage-mediated inflammation in adipose tissue and the liver in NAFLD development and progression, highlighting the clinical implications of triggers and targets of macrophage activation towards a "maladaptive" phenotype.

\section{Tissue Macrophage Polarization and Related Inflammation}

Macrophages display high degrees of plasticity and heterogeneity. Functionally, macrophages can be divided into M1 to M2 subtypes that can be generated under different conditions $[12,13]$. However, it is currently recognized that M1 and M2 phenotypes describe only extreme states towards which macrophages can be activated, because of several additional states that are distinct from both $\mathrm{M} 1$ and $\mathrm{M} 2$ or that simultaneously exhibit characteristics of M1 and M2 polarization $[14,15]$. Even this implies that the pathogenesis of an inflammatory disease, such as NAFLD, could be characterized by a more complex pattern of shapes and functions that mark macrophages; we limited our literature review to the current characterization of M1 and M2 in general and NAFLD.

It has been reported that in vitro treatment with interferon- (IFN-) $\gamma$, TNF- $\alpha$, and LPS induces M1 macrophage polarization. These M1 macrophages are considered proinflammatory or "classically activated" because they produce proinflammatory cytokines such as IL-1 $\beta$, IL-6, IL-8, IL-12, and TNF- $\alpha$ and play a pivotal role in the triggering of tissue injury. By contrast, M2 macrophages differentiate in response to IL-4, IL-13, and IL-10 and are involved in tissue repair and efficient phagocytosis of cellular debris (efferocytosis). Therefore, they are considered tissue-repairing or "non-classically activated" macrophages [13]. Interestingly, wound healing is promoted by M2 macrophages through extracellular matrix (ECM) remodelling and recruitment of fibroblasts [16]. Furthermore, M2-secreted cytokines may support the function of T helper 2 cells. Finally, M2 macrophages may secrete a variety of matrix metalloproteases (MMPs), promoting the clearance of apoptotic cells and cellular debris [13]. This evidence highlights that M2 macrophages are versatile cells sharing several subtypes with different functions that appear to be dual. However, in physiological conditions, the main role of M2 macrophages is to create an anti-inflammatory milieu and promote tissue repair in the case of injury such as in the liver $[17,18]$. During this process, the balance between TGF- $\beta$-dependent deposition of new ECM and its 


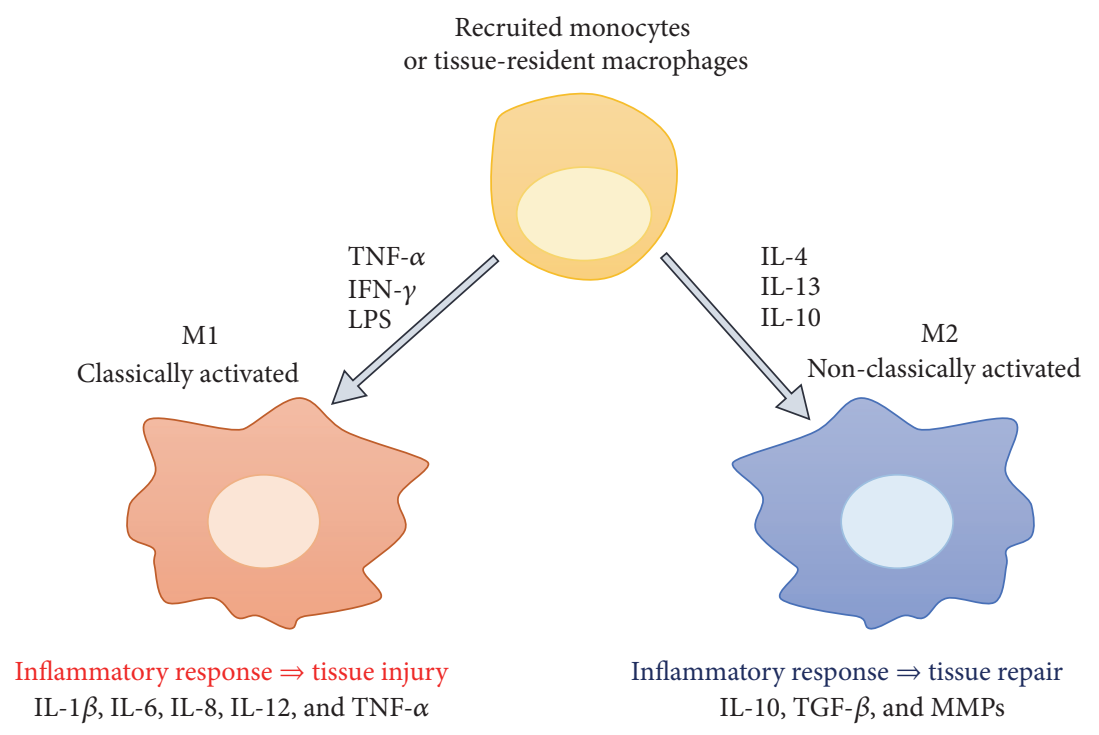

FIGURE 2: Schematic summary of macrophage polarization. Monocytes from peripheral blood differentiate in response to mediators in tissues, giving rise to different subsets: classically (M1) or alternatively (M2) activated macrophages that, respectively, lead to "bad" or "good" proinflammatory response.

MMPs-mediated degradation promotes tissue repair but not pathological fibrosis. However, when the lesion persists M2 macrophages take an important profibrotic role and this cell population starts to secrete a very large amount of profibrotic factors such as TGF- $\beta$ and galectin-3, as already reported in renal fibrosis [19].

The differentiation of tissue macrophages in $\mathrm{M} 1$ and $\mathrm{M} 2$ subsets is summarized in Figure 2.

In general, M1 and M2 macrophages exhibit different cell surface markers. M1 macrophages express high levels of CD80, CD86, CD68, and major histocompatibility complex class II [20], whereas M2 macrophages display an overexpression of other markers, including CD206, CD163, arginase1 (Arg-1), dectin-1, scavenger receptors A and B-1, and C$\mathrm{C}$ motif chemokine receptor-2 (CCR2) [15]. These and other markers of M1 and M2 macrophages are reported in Table 1.

Several inflammatory signals and transcription factors are involved in regulating macrophage polarization, including activation of the canonical interferon regulatory factor/signal transducer and activator of transcription (IRF/STAT) signalling, TLR-4/nuclear factor (NF)- $\kappa \mathrm{B}$ signalling, and transcription factors such as proliferatoractivated receptors (PPARs) [21].

Understanding the above-mentioned mechanisms that drive monocyte recruitment, resident macrophage polarization, and the dissection of signalling pathways targeted by macrophage polarization may be critical to elucidate the precise role of adipose tissue macrophages (ATMs) and liver macrophage polarization during tissue necroinflammation in NASH. Therefore, in the next paragraphs we will discuss the general concepts and current evidence concerning inflammation and macrophage polarization in adipose and liver tissue in both human and experimental models of NAFLD.

\section{Adipose Tissue Inflammation}

3.1. General Characteristics. Adipose tissue is a complex immune organ composed of stromal-vascular cells (adipocytes and preadipocytes) and immune resident cells, including ATMs, T helper cells, cytotoxic T cells, B regulatory cells, and $\mathrm{T}$ regulatory cells, all of which play a role in maintaining immune balance [22].

In adipose tissue, M1 and M2 macrophages are phenotypically different. M1 macrophages express CD11b, CD11c, and $\mathrm{F} 4 / 80$ and secrete TNF- $\alpha$, IL- $1 \beta$, IL-6, nitric oxide (NO), and leukotriene B4, while M2 macrophages express CD11b, F4/80, CD301, and CD206 and produce anti-inflammatory cytokines such as IL-10 [23, 24]. Further markers for M1 and M2 ATMs are extensively reviewed by Hill et al. [25].

ATMs dispersed throughout lean adipose tissue have a predominant M2-like phenotype that helps to maintain local homeostasis [26]. Murine models of diet-induced obesity exhibit remodelling of the epididymal fat depot characterized by adipocyte death, ATM accumulation, and increase of depot weight [26]. In this context, the M1 phenotype appears to be primarily involved in tissue damage, proinflammatory cytokine secretion, leukocyte recruitment, and adipocyte expansion [27]. In obesity, high numbers of macrophages, mainly expressing M1 markers, accumulate in white adipose tissue (WAT) [28]. Over 90\% of these macrophages surround dead adipocytes and form crown-like structures (CLS) [29]. Necrotic-like adipocytes are pathologic hallmarks of obesity and probably regulate macrophage homing in inflamed adipose tissue. In fact, necrotic-like adipocytes closed to multinucleate giant ATMs that secrete TNF- $\alpha$ and drive M1 macrophage response [28]. In contrast, apoptotic adipocytes induce M2 macrophage infiltration [29]. 
TABLE 1: Typical surface markers and functions in M1 and M2 macrophages.

\begin{tabular}{lll}
\hline M1 markers & Major function & Ref. \\
\hline CD80 (B7-1) & T cell activation and survival & {$[15]$} \\
CD86 (B7-2) & T cell activation and survival & {$[15]$} \\
MHC-II & Exogenous antigen presentation & {$[15]$} \\
CD11c & Phagocytosis & {$[17]$} \\
TLR4 & Pathogen recognition & {$[18]$} \\
Mincle & Phagocytosis and proinflammatory cytokines & \\
\hline M2 markers & Major function & {$[19]$} \\
\hline CD206 & Phagocytosis, antigen presentation, and resolution of inflammation & \\
CD163 & Tolerance induction and tissue regeneration & {$[15]$} \\
Dectin-1 & Chemotaxis & {$[15]$} \\
CD301 & Cell adhesion, cell-cell signalling, and glycoprotein turnover & [15] \\
Arginase-1 & Suppression of clearance of intracellular pathogens & \\
\hline
\end{tabular}

M1 accumulation macrophages in CLS are observed in fibrotic adipose tissue and M2 macrophages colocalization is associated with collagen VI, suggesting that M2 towards M1 polarization is a potential hallmark of inflammation/fibrosis in the adipose tissue [30].

It has been reported that macrophage-inducible C-type lectin (Mincle) is activated by endogenous ligands secreted by dead adipocytes and drives ATM migration in the course of CLS organization [31]. Mincle has previously been described as a proinflammatory marker of $\mathrm{M} 1$ polarization stimulated by TLR-4/nuclear factor- (NF-) $\kappa \mathrm{B}$ signalling, which is the main pathway involved in ATM activation [32, 33]. Another gene that may play a regulatory role during adipose tissue resident macrophage differentiation is Tribbles homolog 1 (Trib1). In fact, Trib-1-deficient mice exhibited more adipose tissue mass and fewer M2 macrophages [34].

Although the exact mechanism by which adipocytes control M1/M2 polarization in obese subjects is poorly known, it is evident that ATMs are crucial for immune-metabolism and their activation is associated with insulin resistance and consequent hepatometabolic effects, including NAFLD. The role of obesity-related inflammation in the development of insulin resistance was first suggested by experimental studies revealing that TNF- $\alpha$ increase/blocking was able to induce/decrease insulin resistance in in vitro and in vivo models [35-37]. However, during the last two decades, a significant advance in this field was recognition of the pivotal role of ATMs in the insulin resistance pathogenesis [38-40]. In particular, these series of studies showed the role of PPAR$\gamma$ in the switch of macrophage phenotype from M1 to M2 and its consequences on insulin resistance $[38,39]$. Moreover, very recently, Lee et al. [41] demonstrated that epididymal natural killer cells have a critical role in controlling local ATM recruitment and adipose tissue inflammation, thereby regulating systemic insulin resistance in obesity.

3.2. Adipose Tissue Inflammation in Rodent Models of NAFLD. It has become increasingly evident that chemokines may play a key role in chronic subacute adipose tissue inflammation that is the common underlying condition of obesity, insulin resistance, and NAFLD [42]. Chemokines are small proteins that are expressed in different cells and tissues and control the trafficking of immune cells to sites of inflammation in a variety of conditions or diseases [43].

In an inflammatory condition, such as that occurring in obese WAT, chemokine (C-C motif) ligand (CCL2) binds its receptor CCR2 on a specific-subtype of circulating Ly $6 \mathrm{C}^{+}$monocytes activating their transmigration and differentiation into M1 macrophages. While, in steady state, Ly $6 \mathrm{C}^{+}$monocytes differentiate into Ly $6 \mathrm{C}^{-}$monocytes that are prone to differentiate into M2 macrophages with an anti-inflammatory cytokine profile and involved in tissue repair $[44,45]$. In high-fat diet (HFD) mice, which exhibit NAFLD features, adipose tissue is characterized by significant macrophage infiltration, inflammation, and tissue remodelling [46]. Moreover, HFD mice exhibit necrotic adipocytes that control $\mathrm{Ly}_{6 \mathrm{C}} \mathrm{C}^{+}$monocyte recruitment and subsequent differentiation into M1 macrophages [47]. Paradoxically, the CCR2 is classified as M2 macrophage marker in the current literature, but CCR2 ${ }^{+}$ATMs express prevalently M1 genes to the detriment of M2 genes during adipose tissue inflammatory response [47]. The overexpression of CCR2 by M1 macrophages in visceral WAT is associated with insulin resistance and consequently with NAFLD [48, 49]. Indeed, pharmacological antagonist of CCR2 reduced liver steatosis in obese and diabetic mice $(\mathrm{db} / \mathrm{db})$, and CCL2 deficiency reduced the accumulation of hepatic triglycerides in HFD and $\mathrm{db} / \mathrm{db}$ mice $[48,50]$.

Another chemokine that may play a role in insulin resistance is CCL5. This chemokine has been found primarily involved in the migration of several immune cells by binding to its cognate receptors CCR1, CCR3, and CCR5 [51]. Kitade et al. [52] demonstrated that CCR5 regulated ATM recruitment and polarization and subsequent development of insulin resistance in WAT of genetically (ob/ob) and HFD obese mice.

In experimental NASH models, visceral adipose tissue of mice is enriched by clusters of $\mathrm{CD} 1 \mathrm{~b}^{+}$macrophages producing IL-6 and TNF- $\alpha$ [53]. Consistently, the development of NASH in apolipoprotein E2 (APOE2) knock-in mice was attributed to activated $\mathrm{CD} 68^{+}$macrophages expressing 
proinflammatory genes in the liver [54]. ApoE regulates hepatic clearance of diet-derived chylomicrons and liverderived low density lipoproteins remnants. In parallel, ApoEdeficient mice develop hyperlipidemia and atherosclerosis [55]. Moreover, M1 macrophage infiltration is frequently related to earlier events during spontaneous insulin resistance in mice [56].

In macrophage migration inhibitory factor- (Mif-) deficient obese mice, $\mathrm{F} 4 / 80^{+} \mathrm{Arg}-\mathrm{1}^{+} \mathrm{IL}-13^{+} \mathrm{M} 2$ macrophages were predominant in the liver and strictly correlated with $70 \%$ reduction in $\mathrm{F} 4 / 80^{+} \mathrm{ATMs}$ and hepatoprotection [57]. Mif is a cytokine that may inhibit the migration of macrophages. In fact, Mif-deficiency did not affect obesity and lipid risk factors but did reduce inflammation in WAT and liver; it also reduced macrophage accumulation in WAT and blunted the expression of ICAM-1 and CD44 that regulate macrophage infiltration [58]. In this context, Mif is considered a potential therapeutic target for reducing the inflammatory component of metabolic and cardiovascular disorders. Consistently, hepatic triglycerides, type I collagen, and TGF- $\beta$ mRNA expression as well as the size of adipocytes in visceral adipose tissue were substantially reduced after suppression of macrophage recruitment [59].

In summary, experimental models in rodents indicate that the kinetics of ATM mobilization seems to be important to establish an inflammatory response that shifts from adipose tissue to the liver, leading to NASH and other related metabolic diseases [60, 61].

3.3. Adipose Tissue Inflammation in Human NAFLD. The shift from M2 to M1 occurs also in adipose tissue of human obese subjects. Indeed, the genes encoding for CCL2, CCL8, CCL7, RANTES, CCL3, and CCL11 chemokines, as well as those encoding for CCR1, CCR2, CCR3, and CCR5, were found upregulated in the adipose tissue of morbidly obese compared with lean subjects [62]. Moreover, CD11c ${ }^{+}$M1 macrophages expressing the inflammatory cytokines IL6 and TNF- $\alpha$ increased in the adipose tissues of insulin resistant patients $[28,63]$.

Histological disturbances in the adipose tissue have been described with significant association between inflammation and ECM deposition. Obese patients with NASH showed high expression of tenascin-C by stromal-vascular fraction cells in a TNF- $\alpha$-dependent manner [64]. Tenascin-C is a glycoprotein member of a damage associated molecular pattern rarely produced in healthy adipose tissue, but intensively synthesized during inflammation [65]. In human adipose tissue, tenascin- $\mathrm{C}$ is highly expressed by preadipocytes after macrophage stimulation by mechanisms involving LPS/TLR4 signalling [66]. In parallel, TLR- $4^{-/-}$obese mice showed attenuated adipose tissue inflammation associated with preferential M2 macrophage polarization [67]. Based on these findings, it is plausible that tenascin-C deposition and LPSdependent ATM polarization are critical to inflammation and ECM remodelling in visceral adipose tissue.

Recently, Du Plessis et al. [68] have analysed the transcriptional profile of subcutaneous and visceral adipose tissue of obese patients undergoing bariatric surgery. The authors found that the expression of proinflammatory genes was significantly increased in NAFLD and NASH patients in direct association with accumulation of CCR2 ${ }^{+} \mathrm{M} 1$ macrophages in visceral adipose tissue. These findings newly highlight that the role of CCR2 as a marker of a specific macrophage subtype is often controversial.

3.4. Possible Targets in ATM Inflammation. Among several potential targets that have been investigated as therapeutic applications in adipose tissue inflammation associated with NAFLD, chemokine/chemokine receptor system, adiponectin, leptin, and galectin- 3 have attracted most attention due to their regulatory capacity on adipocyte and macrophage differentiation [42, 69-71].

As mentioned above, several lines of evidence demonstrated that CCR2 is crucial even if not exclusively responsible for ATM recruitment, thus suggesting the CCL2/CCR2 axis as a main target for therapy. Indeed, dampening ATM accumulation and consequent inflammation, via monocyte chemoattractant CCL2/CCR2 pharmacological inhibition, Tamura et al. [50] showed an improvement of obesity and related metabolic disorders, such as insulin resistance and hepatic steatosis in $\mathrm{db} / \mathrm{db}$ mice. Moreover, recently it has been reported that macrophage-targeted delivery of small interference RNA against CCR2 inhibited ATM recruitment and accumulation in adipose tissue, thus reducing the downstream effects of obesity-induced inflammation [72].

Adiponectin has been described as an adipocyte-specific protein playing a positive role in the development of insulin resistance and atherosclerosis. It is negatively correlated with adiposity and its level is substantially reduced during obeserelated inflammation [73]. Accordingly, adiponectin protein and mRNA levels are inversely correlated to TNF- $\alpha$ levels [74]. In humans, adiponectin induced M2 polarization and attenuated the expression of M1 markers by ATMs and stromal-vascular cells of adipose tissue [75]. Recently, it has been reported that macrophage polarization is crucial for the regulation of adiponectin receptor expression and differential adiponectin-mediated macrophage inflammatory responses [76]. Adiponectin reduces lipolysis in murine adipocytes [77]. The protective role of adiponectin was demonstrated in nSREBP-1c/adiponectin double-transgenic mice. The nSREBP-1c transgenic mice overexpress the nuclear sterol regulatory element-binding protein 1c (nSREBP-1c) in adipose tissue and develop hypoadiponectinemia and spontaneous liver disorders consistent with human NASH. The nSREBP-1c/adiponectin double-transgenic mice showed normal liver functions associated with the restoration of hepatic adiponectin production and circulating adiponectin levels [78]. Moreover, adiponectin-deficient mice exposed to HFD develop NASH-related fibrosis [79]. Previously, Nawrocki and colleagues demonstrated that adiponectindeficient mice lost hepatic insulin sensitivity and response to PPAR- $\gamma$, indicating that adiponectin contributes to PPAR- $\gamma$ mediated improvements in glucose tolerance [80]. A recent metabolomic profiling of adiponectin-deficient mice indicated that lysophospholipid metabolism and $\omega$-oxidation of fatty acids are directly regulated by adiponectin [81]. 
These findings suggest that adiponectin can be an antiinflammatory protein with therapeutic potential to ameliorate symptoms of metabolic syndrome and NASH. However, it has been demonstrated that adiponectin should be used with caution because in M1 macrophages it may induce proinflammatory cytokines, whereas, in M2 macrophages, it may induce the anti-inflammatory cytokines [82].

Leptin is another important crucial adipokine involved in the pathogenesis of hepatometabolic effects of obesity. Indeed, it is known as a potent regulator of feeding behaviour and body weight, which has emerged by some seminal studies carried out in different mouse models of obesity $[6,83]$.

Noteworthily, the leptin receptor was found also on most immune cells including monocytes and macrophages. Moreover, as mentioned in previous paragraphs, ob/ob and $\mathrm{db} / \mathrm{db}$ obese mice, respectively, deficient for leptin and leptin receptor, display a reduced ATM infiltration and inflammation [37]. Acedo et al. [71] showed that macrophages exposed to leptin treatment may promote a M2-like phenotype but induced proinflammatory cytokines release, such as TNF- $\alpha$ and IL-6. Luan et al. [84] demonstrated that the injection of leptin into ob/ob mice caused upregulation of circulating norepinephrine, increase of the cAMP content in epididymal fat pads, and HDAC4 dephosphorylation in WAT, triggering anti-inflammatory signals in ATMs.

Galectin-3 is a multifunctional $\beta$-galactoside binding protein firstly described on the macrophage surface [85] and widely associated with fibrosis in distinct tissues [86]. Galectin-3 interacts with distinct types of ECM glycoproteins, including tenascin- $\mathrm{C}$ [87]. As described above, tenascin- $\mathrm{C}$ is widely correlated with proinflammatory events during adipose tissue inflammation, but the interaction with galectin3 during this process is poorly understood. In human adipose tissue, galectin- 3 is synthesized predominantly by preadipocytes and activated macrophages [88]. Obese subjects are characterized by increased serum levels of galectin3 that are directly correlated to growing body mass and age, as well as upregulation of circulating levels of leptin, resistin, and IL-6 [89].

In mice, recombinant galectin-3 induces preadipocyte proliferation [88]. Obese galectin-3 deficient mice are marked by increased visceral adipose tissue mass followed by accumulation of M1 macrophages. In contrast, in the same mice $\mathrm{CD} 4^{+} \mathrm{CD} 25^{+}$FoxP $^{+}{ }^{+} \mathrm{T}$ regulatory cell and $\mathrm{M} 2$ macrophage numbers decreased [90]. In macrophages, galectin-3 exhibits a high-affinity binding for advanced glycosylation end products (AGE), interfering with the pathogenesis of diabetic complications and other metabolic disorders [91]. Deficiency of galectin-3 corroborates with the pancreatic and renal damage associated with AGE accumulation and M1 polarization [92]. However, it is not clear if galectin-3 acts as a receptor for AGE (RAGE) in the course of adipose tissue inflammation and ATM differentiation.

The adipose tissue is able to modulate the expression of galectin- 3 on macrophages. In vitro, preadipocytes inhibited the expression of galectin-3 by a specific subpopulation of macrophages, known as peritoneal-C2D macrophages, which retains plasticity in response to different microenvironments. Peritoneal-C2D macrophages that migrated to
WAT expressed higher levels of galectin-3 than macrophages that moved to brown adipose tissue [93]. Moreover, in the course of monocyte-to-macrophage differentiation, galectin3 mRNA and protein levels are substantially upregulated by M2 macrophages when compared with M1 macrophages [94].

Galectin-3 role on NAFLD pathogenesis has given mixed results [95, 96]. Recent studies highlight that galectin-3 targeting drugs may improve NAFLD-related liver damage, including intraportal and intralobular inflammatory tissue infiltrate, in mouse models [97]. Very recently, Li et al. [98] have demonstrated that galectin-3 knockout mice are protected from inflammation and insulin resistance. The authors showed that a small inhibitor of galectin-3 reduced insulin resistance in HFD mice by improving insulin sensitivity in myocytes and hepatocytes. This last study strongly supports the use of galectin-3 inhibitors as a new approach to treat obesity-related insulin resistance and its comorbidities.

However, to date, it is not clear if galectin-3 is crucial for M1/M2 polarization in both adipose tissue and liver during NAFLD and if the use of specific inhibitors against this protein may rescue $\mathrm{M} 2 / \mathrm{M} 1$ ratio in these tissues.

\section{Liver Tissue Inflammation}

4.1. General Characteristics. Representing $80-90 \%$ of all tissue macrophages in the body, Kupffer cells (KCs) are located in the hepatic sinusoids and are central to innate immunity [99]. In normal conditions, this cell population can selfrenew during adult life without the contribution of circulating monocytes [100]. Functionally, two subgroups of KCs can be recognized based on their phagocytic capabilities and cytokine production [101]. KCs in normal conditions exhibit an M2-like phenotype and express several receptors such as TLRs [102]. In the presence of TLR ligands, KCs become immunogenic and can induce $\mathrm{T}$ cell activation and the generation of an efficient cytotoxic T-lymphocytes response [102]. Furthermore, KCs are involved in the clearance of apoptotic cell debris and iron homeostasis via the expression of scavenger receptors. KCs can interact with multiple immune cells within the sinusoids, including $\mathrm{T}$ cells, dendritic cells, hepatic stellate cells (HSCs), and innate lymphocytes [102]. In inflammatory processes, KCs primarily drive the influx of inflammatory leukocytes such as neutrophils and monocytes.

Interestingly, KCs participate in the constitution of facultative stem cell niches in rodent and human liver; in adult liver, bipotential stem/progenitor cells (HPCs) are present and located in the finer branches of the biliary tree. HPCs minimally contribute to the normal turnover of liver parenchymal cells but are activated in the context of liver injuries [103]. The activation of HPCs is sustained by a specialized niche that furnishes several key signals driving HPC activity [104]. In normal conditions, HPCs are surrounded by endothelial cells, HSCs, and KCs, which release paracrine signals for the maintenance of the stem/progenitors in a quiescent state. In diseased livers, activated HSCs and inflammatory macrophages can produce distinct paracrine signals determining HPC activation and proliferation [104]. 
Moreover, in chronic liver diseases, macrophages are able to activate the canonical Wnt pathway in HPCs triggering their differentiation towards hepatocyte [105]. In particular, the efficient phagocytosis of the debris determines the secretion of WNT3a by KCs, thus activating the canonical Wnt pathway in nearby HPCs and triggering their differentiation towards hepatocyte [106].

Therefore, KCs are key orchestrators of cellular processes in healthy and injured liver. As discussed in the next paragraphs, several studies have indicated that KCs are central in numerous molecular and cellular frameworks and have a pivotal role in NAFLD-related inflammatory processes and fibrosis [106-116].

4.2. KCs and Liver Tissue Inflammation in NAFLD Animal Models. Experimental models have demonstrated that the activation of KCs represents a central event in the initiation and progression of liver injury $[107,108]$. The central role of KCs in the pathogenesis of NAFLD has been suggested by several studies in mouse models where the ablation of KCs determined the marked reduction of hepatic insulin resistance and inflammation in diet-induced steatosis [109, 110]. In experimental NASH, macrophages are characterized by the accumulation of large amounts of toxic lipids $[99,111]$ and cholesterol crystals [112]; fat-laden KCs exhibit a switch to a proinflammatory (M1) phenotype, which is reversible by inhibition of lipogenesis $[99,113]$. Moreover, data obtained by different research groups showed that chemical depletion of KCs was able to prevent the release of proinflammatory cytokines and to alleviate liver damage [114].

In the pathogenesis of NAFLD, the hepatic macrophage pool orchestrates several interactions and crosstalk among resident or recruited cells, thus driving inflammatory processes. In this context, several cellular signalling pathways trigger macrophage activation.

TLRs are able to induce $\mathrm{KC}$ activation towards the M1 phenotype; TLR-4 ablation determines the reduction of liver damage and the depletion of KCs in mice with NASH [115]. Similarly, leptin exerts proinflammatory effects triggering KC activation by a peroxynitrite-dependent mechanism [116]. Leptin can also stimulate inducible nitric oxide synthases (iNOS) and the resultant nitric oxide (NO) can react to produce peroxynitrite, a strong physiological oxidant, and can activate KCs towards a M1 phenotype [116]. In the context of NAFLD and metabolic syndrome, the conversion of arginine to NO and citrulline by NOS and its conversion to ornithine and urea by arginases have been of special interest. Induction of iNOS is a hallmark of M1 macrophages with the consequent production of oxidative stress [117]. Arg-1 is a key marker of M2 macrophages and confers anti-inflammatory properties by substrate competition with iNOS and through other mechanisms; M2 KCs can promote apoptosis of M1 KCs by an arginase-dependent mechanism, limiting liver injury and NASH progression [108]. Similarly, arginase- 2 competes with iNOS for NO substrate and the balance between these two enzymes plays a crucial role in regulating immune responses and macrophage activation; arginase 2-knockout mice fed with a HFD showed profound changes in their livers, characterized by significant steatosis, inflammation, and marked M1 macrophage infiltration [118].

In general, signals leading to macrophage activation converge on two main downstream pathways, nuclear factor(NF-) $\kappa \mathrm{B}$ and C-Jun N-terminal kinase (JNK) [119]. The JNK pathway is activated by reactive oxygen species, saturated free fatty acid, and cholesterol crystallization [119, 120]. Moreover, $\mathrm{NF}-\kappa \mathrm{B}$ is a transcription factor that acts as a key regulator of inflammation and cell death and is activated by various stimuli, such as TLRs, IL-1 $\beta$, and TNF- $\alpha$ [111]. Interestingly, in mice with $\mathrm{NASH}$, hepatocytes with large lipid droplets and cholesterol crystals are surrounded by activated KCs aggregated in hepatic CLS [121]. The administration of cholesterollowering drugs causes the dissolution of cholesterol crystals and disperses CLS in obese mice [122]. All of these effects are associated with reduction of JNK activation and reversal of NASH [120].

Once activated towards the M1 phenotype, KCs secrete a variety of factors influencing inflammation and fibrosis. IL$1 \beta$ is mainly produced by TLR-activated macrophages and has potent inflammatory effects; the lack of IL- $1 \alpha$ or IL$1 \beta$ inhibits transformation of steatosis to steatohepatitis and liver fibrosis in hypercholesterolemic ApoE-deficient mice [123]. Stienstra et al. [124] demonstrated that IL-1 $\beta$ was released by M1-polarized KCs and that this cytokine may promote triglyceride synthesis in hepatocytes by decreasing PPAR- $\alpha$ transactivating activity, which, in turn, inhibited fatty acid oxidation. Furthermore, selective deficiency of IL$1 \alpha$ in KCs reduces liver inflammation and expression of inflammatory cytokines [125]. In NASH, activated KCs also produce CCL2 that contributes to the recruitment of circulating monocytes and macrophages into the inflamed liver [7]. Indeed, choline-deficient amino acid-defined diet-induced steatosis, inflammatory cell infiltration, and liver fibrosis with increased hepatic expression of CCR2 and CCL2, while the KC depletion improved NASH with a decrease of CCL2 expression and recruitment of Ly6 $\mathrm{C}^{-}$monocytes that exhibit a typical M2 anti-inflammatory phenotype [126].

The importance of macrophage recruitment in $\mathrm{NASH}$ is further confirmed in macrophage migration inhibitory factor-knockout mice, which show higher fatty degeneration, liver inflammation, and macrophage recruitment [57].

Activated KCs can secrete TNF superfamily ligands such as TNF- $\alpha$ and TNF-related apoptosis-inducing ligand (TRAIL), thus inducing inflammation and apoptosis of adjacent hepatocytes [127]. The production of TNF- $\alpha$ by KCs contributes to hepatocyte apoptosis, increases monocyte recruitment, and is crucial for triggering NASH development [99]. Interestingly, the engulfment of KCs with apoptotic bodies can further stimulate the generation of ligands of the death receptor-signalling pathway, including TNF- $\alpha$ [128]. Experimentally, gadolinium chloride (a KC toxicant) attenuated the phagocytosis of apoptotic body and the production of ligands for death receptors by KCs; similar results were obtained by the inhibition of hepatocyte apoptosis [128]. This approach results in the attenuation of neutrophil infiltration and in the reduction of HSC activation, confirming the role of KCs and TNF- $\alpha$ in liver inflammation and fibrosis. 
Recently, the role of TRAIL signalling in obesity-associated inflammation has been further defined; genetic deletion of TRAIL receptor in obese mice suppressed NASH and reduced $\mathrm{KC}$ activation and accumulation of inflammatory macrophages in liver [129].

4.3. KCs and Liver Fibrosis: Molecular and Cellular Crosstalk in Murine Models. The spectrum of liver macrophage activation is also relevant for fibrosis progression in NAFLD. Recent studies have demonstrated the antifibrotic properties of KCs, which acting as M2 macrophages can produce a variety of MMPs, enhancing ECM degradation [130]. On the other side, M1 macrophages trigger fibrogenesis mainly by stimulating HSCs [111]. In normal conditions, HSCs are quiescent cells [131]. However, as a consequence of liver injuries, HSCs transdifferentiate into activated myofibroblast-like cells [132]. Activated HSCs begin to secrete ECM components and produce tissue inhibitors of metalloproteinases (TIMPs), thus altering the balance between ECM synthesis and degradation and leading to fibrosis [131].

Several molecular mechanisms form the basis for crosstalk between KCs and HSCs. M1 macrophages can activate HSCs by releasing TGF- $\beta$ and other profibrogenetic cytokines, thus promoting collagen deposition and stimulating the production of TIMP-1 [133]. Moreover, KCs can promote HSC survival, inducing NF- $\kappa \mathrm{B}$ signalling via TNF$\alpha$ and IL-1 secretion [131, 133]; furthermore, the secretion of several chemokines (i.e., CCL2, CCL3-5, CCL7 and CCL8) by macrophages can promote HSC migration [111]. As a consequence, $\mathrm{KC}$ depletion in mice models attenuates the progression of liver fibrosis [131].

On the other hand, KCs could be also implicated in promoting fibrosis resolution. In this context, specific subtypes of macrophages (M2) can secrete MMPs and TRAIL contributing to ECM degradation and HSC apoptosis, respectively [134].

Recent evidence indicates that HPC activation has a prominent role in the progression of liver fibrosis. Under pathological conditions, the activation of HPCs determines the appearance of the so-called ductular reaction (DR), which was recently found to be a main driver of liver fibrogenesis $[131,135]$. In this context, the hepatic macrophage pool can influence the HPC response [131, 135]. Among the variety of macrophage cytokines, TNF-like weak inducer of apoptosis (TWEAK) has a key role in the expansion of undifferentiated HPCs [135]. Moreover, the capability of macrophages to remodel ECM influences the composition of the HPC niche and sustains HPC response and DR [105, 131, 135]. In turn, activated HPCs secrete a variety of substances such as TGF- $\beta$, Hedgehog (Hh) ligands, Osteopontin (OPN), and adipokines that are able to stimulate KCs and HSC, thus influencing inflammation and fibrogenesis [135].

4.4. Role of KCs in Liver Tissue Inflammation and Fibrosis in Human NAFLD. The role of KC activation in liver inflammation and fibrosis has been also elucidated in patients with NAFLD. Like adipose tissue in obesity, livers with NASH are characterized by the appearance of hepatic CLS
[136]. These unique histological structures are correlated with hepatic inflammation and fibrosis [121]. Interestingly, in obese children with NAFLD, subcutaneous adipose tissue has CLS strictly correlated with liver fibrosis scores and diabetes risks [137].

The polarization of liver-resident macrophages is a key feature in NASH development. As previously indicated, CD163 is a surface scavenger receptor for haptoglobinhemoglobin complexes expressed almost exclusively on M2 macrophages and monocytes. However, upon macrophage activation, CD163 is shed as its soluble form (sCD163) that can be measured in the circulation and serve as a biochemical marker of macrophage M1 activation [138]. sCD163 was associated with changes in NAFLD and metabolic profile during lifestyle intervention in obese children and in morbidly obese patients after bariatric surgery [139]. sCD163 increases in parallel with the severity of NAFLD and is reduced by lifestyle or surgical intervention, thus suggesting that macrophage M1 activation is reversible [139]. In this context, M2 KC polarization might protect against fatty liver disease morbidly injury [108].

Although NAFLD is conventionally assessed histologically for lobular features of inflammation, development of portal inflammation and fibrosis appears to be associated with disease progression in human patients [140]. The portal infiltrate is mostly constituted of macrophages and portal macrophage infiltration was the first change detected in patients with early NASH, even before elevated expression of proinflammatory cytokines. The presence of portal inflammation in NAFLD patients provides a link between macrophages and HPC activation. In both adult and paediatric patients, NASH development and fibrosis are associated with HPC activation and DR [131, 140, 141]. In parallel with animal studies, the portal macrophage infiltrate in human NAFLD may contribute directly to fibrogenesis as well as influence the fate of HPCs, regulating the balance between liver repair and fibrosis.

4.5. Possible Targets in Liver Tissue Inflammation. As discussed thus far, the recruitment of liver-resident macrophages (mainly KCs) and their polarization is a pivotal factor in obesity-associated insulin resistance and NAFLD/NASH. Therefore, even if there are not currently established therapies to revert NASH, several promising treatments targeting the hepatic activation and polarization of KCs in NASH are being developed [142].

The fact that KC recruitment and activation may be driven by chemokine/chemokine receptor system has prompted several experimental studies with pharmacological inhibitors of these pathways $[136,143]$. In fact, Baeck et al. [136] found that mNOX-E36, which inhibited CCL2 by binding, reduced the amount of intrahepatic macrophages and proinflammatory cytokines and ameliorated hepatic steatosis in methionine-choline-deficient diet mice with NASH. Moreover, recently, cenicriviroc, a dual CCR2/CCR5 antagonist, was reported to be able to significantly reduce fibrosis and the NAFLD activity score in a NASH model [143]. On this basis, a phase 2 clinical trial addressing the 
effect of cenicriviroc in NASH patients with fibrosis is currently ongoing [144].

Macrophage activation can be influenced by the $G$ protein-coupled receptor (GPR) 120. The protein GPR120 may modulate macrophage response by decreasing M1 proinflammatory and increasing M2 anti-inflammatory gene expression [108]. GPR120 exerts robust and broad antiinflammatory effects, acting as a negative feedback signal on NF- $\kappa \mathrm{B}$ phosphorylation induced by TLRs and the TNF $\alpha$ cascade $[145,146]$. Similarly, human KCs express GPR120 [147] and this expression in NAFLD patients can be modulated by the treatment with docosahexaenoic acid (DHA), the major dietary N-3 long-chain polyunsaturated fatty acid (LC-PUFA) [148-150]. Unfortunately, the effect of LC-PUFA alone seems to be restricted to early NAFLD stages. However, Carpino et al. [151] have recently reported that treatment with DHA determined a macrophage polarization towards a M2 phenotype in correlation with reduction of proinflammatory cytokines levels, increased macrophage apoptosis, and upregulation of macrophage Wnt3a expression in children with NASH.

Although the role of galectin-3 in NASH appears to be controversial, the antifibrotic effect of its absence is a certainty $[95,152]$. Preliminary results of a randomized clinical trial with GR-MD-02, a galactoarabino-rhamnogalacturonan polysaccharide that is able to block the galectin-3 receptor, have been recently reported, thus supporting the planning of a phase 2 clinical trial in advanced fibrosis due to NASH [153].

Moreover, OPN represents an interesting molecular tool linking the crosstalk among KCs, HSCs, and HPCs. In the liver, OPN is produced by several cell types including T cells, macrophages, and HPCs [131, 154]. Upregulation of hepatic OPN was found in both humans and rodents with advanced $\mathrm{NASH}$, while OPN-deficient mice were protected against NASH and fibrosis $[131,135,154]$. OPN may stimulate collagen synthesis in HSCs and exert an autocrine effect on HPCs $[135,154]$. Furthermore, the ablation of OPN reduced HPC response, prevented fibrogenesis, and improved liver regeneration [155]. Interestingly, Kwon et al. [156] reported that Hh signalling can promote liver inflammation through OPNmediated macrophage activation contributing to NAFLD progression, while the inhibition of Hh signalling can ameliorate hepatic inflammation in mice with NAFLD, highlighting the therapeutic propensity of Hh inhibitors [156].

\section{Conclusion}

ATM and hepatic macrophage polarization may be histological hallmarks of future preventive diagnoses, considering the earlier events on adipose tissue in comparison with those occurring in the liver of NAFLD patients. In order to confirm this hypothesis, further clinical studies on the expression of specific markers of M1 and M2 polarization are required. Several markers may differentiate M1 from the M2 subset, but to date only a few of them have been investigated in NAFLD and correlated with disease progression or with response to therapy. In this regard, it is also important to point out that functional heterogeneity of macrophages in
NAFLD, such as in other diseases, is associated with a similar heterogeneity of the expression of specific markers that we overviewed here. A tissue array of the expression of M1/M2 populations in adipose tissue and liver could elucidate the dynamic changes of macrophage polarization and molecular networks orchestrating the switch of macrophage phenotype during NAFLD pathogenesis.

In addition, in both adipose tissue and liver tissue, it is necessary to investigate (i) the potential triggers that induce macrophage polarization towards a M1 "dark side" phenotype; (ii) the role of common molecular pathways; (iii) the link between triggers and liver necroinflammation and fibrosis; and (iv) the real role of M2 macrophages in NAFLDrelated fibrogenesis. The dissection of these mechanisms could help in the identification of potential new therapeutic targets, improving the pharmacological therapy for pathophysiologic events of necroinflammation, ballooning, and fibrosis.

\section{Abbreviations}

AGE: $\quad$ Advanced glycosylation end products

ApoE2: $\quad$ Apolipoprotein E2

Arg-1: $\quad$ Arginase-1

ATM: $\quad$ Adipose tissue macrophage

CCL: $\quad$ Chemokine (C-C motif) ligand

CCR: $\quad \mathrm{C}-\mathrm{C}$ motif chemokine receptor

CLS: $\quad$ Crown-like structures

DHA: Docosahexaenoic acid

DR: Ductular reaction

ECM: $\quad$ Extracellular matrix

GPR120: G protein-coupled receptor 120

HFD: High-fat diet

Hh: Hedgehog

HIF1: Hypoxia-inducible factor-1

HPCs: Hepatic progenitor cells

HSCs: Hepatic stellate cells

IFN- $\gamma$ : Interferon-gamma

IL: $\quad$ Interleukin

iNOS: Inducible nitric oxide synthases

JNK: Jun N-terminal kinase

KCs: $\quad$ Kupffer cells

LC-PUFA: Long-chain polyunsaturated fatty acids

LPS: Lipopolysaccharide

MCP-1: Monocyte chemoattractant protein-1

MIF: $\quad$ Migration inhibitory factor

Mincle: Macrophage-inducible C-type lectin

MMPs: $\quad$ Matrix metalloproteases

NAFLD: Nonalcoholic fatty liver disease

NASH: Nonalcoholic steatohepatitis

NF- $\kappa$ B: $\quad$ Nuclear factor $-\kappa B$

NO: $\quad$ Nitric oxide

nSREBP-1c: Nuclear sterol regulatory element-binding protein $1 c$

OPN: Osteopontin

PPARs: Peroxisome proliferator-activated receptors

RAGE: Receptor for AGE

TGF- $\beta 1$ : Transforming growth factor-beta 1 
TIMPs: Tissue inhibitors of metalloproteinases

TLR: Toll-like receptor

TNF- $\alpha$ : Tumour necrosis factor-alpha

TRAIL: TNF-related apoptosis-inducing ligand

Tribl: Tribbles homolog 1

TWEAK: TNF-like weak inducer of apoptosis

WAT: White adipose tissue.

\section{Competing Interests}

The authors declare that there is no conflict of interests.

\section{Authors' Contributions}

Valerio Nobili and Eugenio Gaudio equally contributed to the manuscript.

\section{Acknowledgments}

Anna Alisi and Valerio Nobili are supported by the Italian Ministry of Health Funds (Fondi di Ricerca Corrente 2015). Felipe L. Oliveira was supported as Special Visiting Researcher by "Science without Borders," a Brazilian Federal Programme by CAPES (Brazil-Italy exchange).

\section{References}

[1] M. E. Rinella, "Nonalcoholic fatty liver disease: a systematic review," The Journal of the American Medical Association, vol. 313, no. 22, pp. 2263-2273, 2015.

[2] S. Singh, A. M. Allen, Z. Wang, L. J. Prokop, M. H. Murad, and R. Loomba, "Fibrosis progression in nonalcoholic fatty liver vs nonalcoholic steatohepatitis: a systematic review and metaanalysis of paired-biopsy studies," Clinical Gastroenterology and Hepatology, vol. 13, no. 4, pp. 643-654, 2015.

[3] M. Blachier, H. Leleu, M. Peck-Radosavljevic, D.-C. Valla, and F. Roudot-Thoraval, "The burden of liver disease in Europe: a review of available epidemiological data," Journal of Hepatology, vol. 58, no. 3, pp. 593-608, 2013.

[4] V. Nobili, G. Svegliati-Baroni, A. Alisi, L. Miele, L. Valenti, and P. Vajro, "A 360-degree overview of paediatric NAFLD: recent insights," Journal of Hepatology, vol. 58, no. 6, pp. 1218-1229, 2013.

[5] G. Musso, E. Paschetta, R. Gambino, M. Cassader, and F. Molinaro, "Interactions among bone, liver, and adipose tissue predisposing to diabesity and fatty liver," Trends in Molecular Medicine, vol. 19, no. 9, pp. 522-535, 2013.

[6] H. Tilg and A. R. Moschen, "Evolution of inflammation in nonalcoholic fatty liver disease: the multiple parallel hits hypothesis," Hepatology, vol. 52, no. 5, pp. 1836-1846, 2010.

[7] A. Sica and A. Mantovani, "Macrophage plasticity and polarization: in vivo veritas," The Journal of Clinical Investigation, vol. 122, no. 3, pp. 787-795, 2012.

[8] L. Miele, V. Valenza, G. La Torre et al., "Increased intestinal permeability and tight junction alterations in nonalcoholic fatty liver disease," Hepatology, vol. 49, no. 6, pp. 1877-1887, 2009.

[9] W. Z. Mehal, "The gordian knot of dysbiosis, obesity and NAFLD," Nature Reviews Gastroenterology and Hepatology, vol. 10, no. 11, pp. 637-644, 2013.
[10] O. E. Frasinariu, S. Ceccarelli, A. Alisi, E. Moraru, and V. Nobili, "Gut-liver axis and fibrosis in nonalcoholic fatty liver disease: an input for novel therapies," Digestive and Liver Disease, vol. 45, no. 7, pp. 543-551, 2013.

[11] G. Baffy, "Kupffer cells in non-alcoholic fatty liver disease: the emerging view," Journal of Hepatology, vol. 51, no. 1, pp. 212-223, 2009.

[12] P. J. Murray, J. E. Allen, S. K. Biswas et al., "Macrophage activation and polarization: nomenclature and experimental guidelines," Immunity, vol. 41, no. 1, pp. 14-20, 2014.

[13] A. Sica, P. Invernizzi, and A. Mantovani, "Macrophage plasticity and polarization in liver homeostasis and pathology," Hepatology, vol. 59, no. 5, pp. 2034-2042, 2014.

[14] J. Xue, S. V. Schmidt, J. Sander et al., "Transcriptome-based network analysis reveals a spectrum model of human macrophage activation," Immunity, vol. 40, no. 2, pp. 274-288, 2014.

[15] P. Ramachandran, A. Pellicoro, M. A. Vernon et al., "Differential Ly-6C expression identifies the recruited macrophage phenotype, which orchestrates the regression of murine liver fibrosis," Proceedings of the National Academy of Sciences of the United States of America, vol. 109, no. 46, pp. E3186-E3195, 2012.

[16] S. Gordon and F. O. Martinez, "Alternative activation of macrophages: mechanism and functions," Immunity, vol. 32, no. 5, pp. 593-604, 2010.

[17] T. T. Braga, J. S. H. Agudelo, and N. O. S. Camara, "Macrophages during the fibrotic process: M2 as friend and foe," Frontiers in Immunology, vol. 6, article 602, 2015.

[18] C. Ju and F. Tacke, "Hepatic macrophages in homeostasis and liver diseases: from pathogenesis to novel therapeutic strategies," Cellular and Molecular Immunology, vol. 13, no. 3, pp. 316-327, 2016.

[19] M. A. Vernon, K. J. Mylonas, and J. Hughes, "Macrophages and renal fibrosis," Seminars in Nephrology, vol. 30, no. 3, pp. 302$317,2010$.

[20] A. Castoldi, C. N. De Souza, N. O. Saraiva Câmara, and P. M. Moraes-Vieira, "The macrophage switch in obesity development," Frontiers in Immunology, vol. 6, article no. 637, 2016.

[21] N. Wang, H. Liang, and K. Zen, "Molecular mechanisms that influence the macrophage M1-M2 polarization balance," Frontiers in Immunology, vol. 5, article 614, 2014.

[22] S. Cinti, G. Mitchell, G. Barbatelli et al., "Adipocyte death defines macrophage localization and function in adipose tissue of obese mice and humans," Journal of Lipid Research, vol. 46, no. 11, pp. 2347-2355, 2005.

[23] P. Fischer-Posovszky, Q. A. Wang, I. W. Asterholm, J. M. Rutkowski, and P. E. Scherer, "Targeted deletion of adipocytes by apoptosis leads to adipose tissue recruitment of alternatively activated M2 macrophages," Endocrinology, vol. 152, no. 8, pp. 3074-3081, 2011.

[24] J. M. Olefsky and C. K. Glass, "Macrophages, inflammation, and insulin resistance," Annual Review of Physiology, vol. 72, pp. 219246, 2010.

[25] A. A. Hill, W. Reid Bolus, and A. H. Hasty, "A decade of progress in adipose tissue macrophage biology," Immunological Reviews, vol. 262, no. 1, pp. 134-152, 2014.

[26] K. J. Strissel, Z. Stancheva, H. Miyoshi et al., "Adipocyte death, adipose tissue remodeling, and obesity complications," Diabetes, vol. 56, no. 12, pp. 2910-2918, 2007.

[27] V. Apostolopoulos, M. P. J. de Courten, L. Stojanovska, G. L. Blatch, K. Tangalakis, and B. de Courten, "The complex immunological and inflammatory network of adipose tissue in 
obesity," Molecular Nutrition and Food Research, vol. 60, no. 1, pp. 43-57, 2016.

[28] C. N. Lumeng, J. L. Bodzin, and A. R. Saltiel, "Obesity induces a phenotypic switch in adipose tissue macrophage polarization," Journal of Clinical Investigation, vol. 117, no. 1, pp. 175-184, 2007.

[29] H. S. Schipper, B. Prakken, E. Kalkhoven, and M. Boes, "Adipose tissue-resident immune cells: key players in immunometabolism," Trends in Endocrinology and Metabolism, vol. 23, no. 8, pp. 407-415, 2012.

[30] M. Spencer, A. Yao-Borengasser, R. Unal et al., "Adipose tissue macrophages in insulin-resistant subjects are associated with collagen VI and fibrosis and demonstrate alternative activation," American Journal of Physiology - Endocrinology and Metabolism, vol. 299, no. 6, pp. E1016-E1027, 2010.

[31] M. Ichioka, T. Suganami, N. Tsuda et al., "Increased expression of macrophage-inducible C-type lectin in adipose tissue of obese mice and humans," Diabetes, vol. 60, no. 3, pp. 819-826, 2011.

[32] M. Tanaka, K. Ikeda, T. Suganami et al., "Macrophage-inducible C-type lectin underlies obesity-induced adipose tissue fibrosis," Nature Communications, vol. 5, article 4982, 2014.

[33] Y. Watanabe, Y. Nagai, H. Honda et al., "Isoliquiritigenin attenuates adipose tissue inflammation in vitro and adipose tissue fibrosis through inhibition of innate immune responses in mice," Scientific Reports, vol. 6, Article ID 23097, 2016.

[34] T. Satoh, H. Kidoya, H. Naito et al., "Critical role of Trib1 in differentiation of tissue-resident M2-like macrophages," Nature, vol. 495, no. 7442, pp. 524-528, 2013.

[35] G. S. Hotamisligil, N. S. Shargill, and B. M. Spiegelman, "Adipose expression of tumor necrosis factor-alpha: direct role in obesity-linked insulin resistance," Science, vol. 259, no. 5091, pp. 87-91, 1993.

[36] K. T. Uysal, S. M. Wiesbrock, M. W. Marino, and G. S. Hotamisligil, "Protection from obesity-induced insulin resistance in mice lacking TNF- $\alpha$ function," Nature, vol. 389, pp. 610-614, 1997.

[37] H. Xu, G. T. Barnes, Q. Yang et al., "Chronic inflammation in fat plays a crucial role in the development of obesity-related insulin resistance," Journal of Clinical Investigation, vol. 112, no. 12, pp. 1821-1830, 2003.

[38] J. I. Odegaard, R. R. Ricardo-Gonzalez, M. H. Goforth et al., "Macrophage-specific PPAR $\gamma$ controls alternative activation and improves insulin resistance," Nature, vol. 447, no. 7148, pp. 1116-1120, 2007.

[39] A. L. Hevener, J. M. Olefsky, D. Reichart et al., "Macrophage PPAR $\gamma$ is required for normal skeletal muscle and hepatic insulin sensitivity and full antidiabetic effects of thiazolidinediones," Journal of Clinical Investigation, vol. 117, no. 6, pp. 16581669, 2007.

[40] S. Fujisaka, I. Usui, A. Bukhari et al., "Regulatory mechanisms for adipose tissue M1 and M2 macrophages in diet-induced obese mice," Diabetes, vol. 58, no. 11, pp. 2574-2582, 2009.

[41] B. Lee, M. Kim, M. Pae et al., "Adipose natural killer cells regulate adipose tissue macrophages to promote insulin resistance in obesity," Cell Metabolism, vol. 23, no. 4, pp. 685-698, 2016.

[42] L. Xu, H. Kitade, Y. Ni, and T. Ota, "Roles of chemokines and chemokine receptors in obesity-associated insulin resistance and nonalcoholic fatty liver disease," Biomolecules, vol. 5, no. 3, pp. 1563-1579, 2015.

[43] C. Gerard and B. J. Rollins, "Chemokines and disease," Nature Immunology, vol. 2, no. 2, pp. 108-115, 2001.
[44] J. Yang, L. Zhang, C. Yu, X. Yang, and H. Wang, "Monocyte and macrophage differentiation: circulation inflammatory monocyte as biomarker for inflammatory diseases," Biomarker Research, vol. 2, article 1, 2014.

[45] S. Yona, K. W. Kim, Y. Wolf et al., "Fate mapping reveals origins and dynamics of monocytes and tissue macrophages under homeostasis," Immunity, vol. 38, no. 1, pp. 79-91, 2013.

[46] C. Duval, U. Thissen, S. Keshtkar et al., "Adipose tissue dysfunction signals progression of hepatic steatosis towards nonalcoholic steatohepatitis in C57Bl/6 mice," Diabetes, vol. 59, no. 12, pp. 3181-3191, 2010.

[47] C. N. Lumeng, J. B. Delproposto, D. J. Westcott, and A. R. Saltiel, "Phenotypic switching of adipose tissue macrophages with obesity is generated by spatiotemporal differences in macrophage subtypes," Diabetes, vol. 57, no. 12, pp. 3239-3246, 2008.

[48] H. Kanda, S. Tateya, Y. Tamori et al., "MCP-1 contributes to macrophage infiltration into adipose tissue, insulin resistance, and hepatic steatosis in obesity," The Journal of Clinical Investigation, vol. 116, no. 6, pp. 1494-1505, 2006.

[49] S. P. Weisberg, D. Hunter, R. Huber et al., "CCR2 modulates inflammatory and metabolic effects of high-fat feeding," Journal of Clinical Investigation, vol. 116, no. 1, pp. 115-124, 2006.

[50] Y. Tamura, M. Sugimoto, T. Murayama et al., "Inhibition of CCR2 ameliorates insulin resistance and hepatic steatosis in $\mathrm{db} / \mathrm{db}$ mice," Arteriosclerosis, Thrombosis, and Vascular Biology, vol. 28, no. 12, pp. 2195-2201, 2008.

[51] T. J. Schall, K. Bacon, K. J. Toy, and D. V. Goeddel, "Selective attraction of monocytes and $\mathrm{T}$ lymphocytes of the memory phenotype by cytokine RANTES," Nature, vol. 347, no. 6294, pp. 669-671, 1990.

[52] H. Kitade, K. Sawamoto, M. Nagashimada et al., "CCR5 plays a critical role in obesity-induced adipose tissue inflammation and insulin resistance by regulating both macrophage recruitment and M1/M2 status," Diabetes, vol. 61, no. 7, pp. 1680-1690, 2012.

[53] M. Fujimoto, K. Tsuneyama, T. Fujimoto, C. Selmi, M. E. Gershwin, and Y. Shimada, "Spirulina improves non-alcoholic steatohepatitis, visceral fat macrophage aggregation, and serum leptin in a mouse model of metabolic syndrome," Digestive and Liver Disease, vol. 44, no. 9, pp. 767-774, 2012.

[54] R. Shiri-Sverdlov, K. Wouters, P. J. van Gorp et al., "Early dietinduced non-alcoholic steatohepatitis in APOE2 knock-in mice and its prevention by fibrates," Journal of Hepatology, vol. 44, no. 4, pp. 732-741, 2006.

[55] A. A. Pendse, J. M. Arbones-Mainar, L. A. Johnson, M. K. Altenburg, and N. Maeda, "Apolipoprotein E knock-out and knock-in mice: atherosclerosis, metabolic syndrome, and beyond," Journal of Lipid Research, vol. 50, pp. S178-S182, 2009.

[56] T. Maeda, I. Noge, and Y. Kagawa, "Infiltration of M1 macrophages into adipose tissue of ddY-H mice preceding spontaneous appearances of insulin resistance," Biological and Pharmaceutical Bulletin, vol. 36, no. 5, pp. 825-832, 2013.

[57] D. Heinrichs, M.-L. Berres, M. Coeuru et al., "Protective role of macrophage migration inhibitory factor in nonalcoholic steatohepatitis," The FASEB Journal, vol. 28, no. 12, pp. 51365147, 2014.

[58] L. Verschuren, T. Kooistra, J. Bernhagen et al., "MIF deficiency reduces chronic inflammation in white adipose tissue and impairs the development of insulin resistance, glucose intolerance, and associated atherosclerotic disease," Circulation Research, vol. 105, no. 1, pp. 99-107, 2009. 
[59] H. Kudo, Y. Yata, T. Takahara et al., “Telmisartan attenuates progression of steatohepatitis in mice: role of hepatic macrophage infiltration and effects on adipose tissue," Liver International, vol. 29, no. 7, pp. 988-996, 2009.

[60] M. C. Stanton, S.-C. Chen, J. V. Jackson et al., "Inflammatory Signals shift from adipose to liver during high fat feeding and influence the development of steatohepatitis in mice," Journal of Inflammation, vol. 8, article no. 8, 2011.

[61] A. Chawla, K. D. Nguyen, and Y. P. S. Goh, "Macrophagemediated inflammation in metabolic disease," Nature Reviews Immunology, vol. 11, no. 11, pp. 738-749, 2011.

[62] J. Huber, F. W. Kiefer, M. Zeyda et al., "CC chemokine and CC chemokine receptor profiles in visceral and subcutaneous adipose tissue are altered in human obesity," The Journal of Clinical Endocrinology \& Metabolism, vol. 93, no. 8, pp. 32153221, 2008.

[63] J. M. Wentworth, G. Naselli, W. A. Brown et al., "Proinflammatory $\mathrm{CD}_{11 c^{+}} \mathrm{CD}_{206^{+}}$adipose tissue macrophages are associated with insulin resistance in human obesity," Diabetes, vol. 59, no. 7, pp. 1648-1656, 2010.

[64] V. Catalán, J. Gómez-Ambrosi, A. Rodríguez et al., "Increased tenascin $\mathrm{C}$ and toll-like receptor 4 levels in visceral adipose tissue as a link between inflammation and extracellular matrix remodeling in obesity," Journal of Clinical Endocrinology and Metabolism, vol. 97, no. 10, pp. E1880-E1889, 2012.

[65] I. A. Udalova, M. Ruhmann, S. J. Thomson, and K. S. Midwood, "Expression and immune function of tenascin-C," Critical Reviews in Immunology, vol. 31, no. 2, pp. 115-145, 2011.

[66] K. Midwood, S. Sacre, A. M. Piccinini et al., "Tenascin-C is an endogenous activator of Toll-like receptor 4 that is essential for maintaining inflammation in arthritic joint disease," Nature Medicine, vol. 15, no. 7, pp. 774-780, 2009.

[67] J. S. Orr, M. J. Puglisi, K. L. J. Ellacott, C. N. Lumeng, D. H. Wasserman, and A. H. Hasty, "Toll-like receptor 4 deficiency promotes the alternative activation of adipose tissue macrophages," Diabetes, vol. 61, no. 11, pp. 2718-2727, 2012.

[68] J. Du Plessis, J. Van Pelt, H. Korf et al., "Association of adipose tissue inflammation with histologic severity of nonalcoholic fatty liver disease," Gastroenterology, vol. 149, no. 3, pp. 635.e14648.e14, 2015.

[69] A. Dhirapong, A. Lleo, P. Leung, M. E. Gershwin, and F.T. Liu, "The immunological potential of galectin-1 and -3 ," Autoimmunity Reviews, vol. 8, no. 5, pp. 360-363, 2009.

[70] T. Kadowaki, T. Yamauchi, H. Waki, M. Iwabu, M. OkadaIwabu, and M. Nakamura, "Adiponectin, adiponectin receptors, and epigenetic regulation of adipogenesis," Cold Spring Harbor Symposia on Quantitative Biology, vol. 76, pp. 257-265, 2011.

[71] S. C. Acedo, S. Gambero, F. G. P. Cunha, I. Lorand-Metze, and A. Gambero, "Participation of leptin in the determination of the macrophage phenotype: an additional role in adipocyte and macrophage crosstalk," In Vitro Cellular and Developmental Biology-Animal, vol. 49, no. 6, pp. 473-478, 2013.

[72] J. Kim, K. Chung, C. Choi et al., "Silencing CCR2 in macrophages alleviates adipose tissue inflammation and the associated metabolic syndrome in dietary obese mice," Molecular Therapy-Nucleic Acids, vol. 5, article e280, 2016.

[73] Y. Arita, S. Kihara, N. Ouchi et al., "Paradoxical decrease of an adipose-specific protein, adiponectin, in obesity," Biochemical and Biophysical Research Communications, vol. 257, no. 1, pp. 79-83, 1999.

[74] P. A. Kern, G. B. Di Gregorio, T. Lu, N. Rassouli, and G. Ranganathan, "Adiponectin expression from human adipose tissue: relation to obesity, insulin resistance, and tumor necrosis factor- $\alpha$ expression," Diabetes, vol. 52, no. 7, pp. 1779-1785, 2003.

[75] K. Ohashi, J. L. Parker, N. Ouchi et al., "Adiponectin promotes macrophage polarization toward an anti-inflammatory phenotype," The Journal of Biological Chemistry, vol. 285, no. 9, pp. 6153-6160, 2010.

[76] C. M. W. Van Stijn, J. Kim, A. J. Lusis, G. D. Barish, and R. K. Tangirala, "Macrophage polarization phenotype regulates adiponectin receptor expression and adiponectin antiinflammatory response," FASEB Journal, vol. 29, no. 2, pp. 636649, 2015.

[77] L. Qiao, B. Kinney, J. Schaack, and J. Shao, "Adiponectin inhibits lipolysis in mouse adipocytes," Diabetes, vol. 60, no. 5, pp. 15191527, 2011.

[78] H. Nakayama, S. Otabe, X. Yuan et al., "Effects of adiponectin transgenic expression in liver of nonalcoholic steatohepatitis model mice," Metabolism: Clinical and Experimental, vol. 58, no. 7, pp. 901-908, 2009.

[79] T. Asano, K. Watanabe, N. Kubota et al., "Adiponectin knockout mice on high fat diet develop fibrosing steatohepatitis," Journal of Gastroenterology and Hepatology, vol. 24, no. 10, pp. 1669$1676,2009$.

[80] A. R. Nawrocki, M. W. Rajala, E. Tomas et al., "Mice lacking adiponectin show decreased hepatic insulin sensitivity and reduced responsiveness to peroxisome proliferator-activated receptor $\gamma$ agonists," Journal of Biological Chemistry, vol. 281, no. 5, pp. 2654-2660, 2006.

[81] Y. Liu, S. Sen, S. Wannaiampikul et al., "Metabolomic profiling in liver of adiponectin-knockout mice uncovers lysophospholipid metabolism as an important target of adiponectin action," Biochemical Journal, vol. 469, no. 1, pp. 71-82, 2015.

[82] C. M. W. van Stijn, J. Kim, A. J. Lusis, G. D. Barish, and R. K. Tangirala, "Macrophage polarization phenotype regulates adiponectin receptor expression and adiponectin antiinflammatory response," The FASEB Journal, vol. 29, no. 2, pp. 636-649, 2015.

[83] J.-P. Bastard, M. Maachi, C. Lagathu et al., "Recent advances in the relationship between obesity, inflammation, and insulin resistance," European Cytokine Network, vol. 17, no. 1, pp. 4-12, 2006.

[84] B. Luan, M. O. Goodarzi, N. G. Phillips et al., "Leptinmediated increases in catecholamine signaling reduce adipose tissue inflammation via activation of macrophage HDAC4," Cell Metabolism, vol. 19, no. 6, pp. 1058-1065, 2014.

[85] M. K. Ho and T. A. Springer, "MAC-2, a novel 32,000 Mr mouse macrophage subpopulation-specific antigen defined by monoclonal antibodies," Journal of Immunology, vol. 128, no. 3, pp. 1221-1228, 1982.

[86] L.-C. Li, J. Li, and J. Gao, "Functions of galectin-3 and its role in fibrotic diseases," Journal of Pharmacology and Experimental Therapeutics, vol. 351, no. 2, pp. 336-343, 2014.

[87] R. Probstmeier, D. Montag, and M. Schachner, "Galectin3 , a beta-galactoside-binding animal lectin, binds to neural recognition molecules," Journal of Neurochemistry, vol. 64, no. 6, pp. 2465-2472, 1995.

[88] K. Kiwaki, C. M. Novak, D. K. Hsu, F.-T. Liu, and J. A. Levine, "Galectin-3 stimulates preadipocyte proliferation and is upregulated in growing adipose tissue," Obesity, vol. 15, no. 1, pp. 32-39, 2007.

[89] J. Weigert, M. Neumeier, J. Wanninger et al., "Serum galectin-3 is elevated in obesity and negatively correlates with glycosylated 
hemoglobin in type 2 diabetes," Journal of Clinical Endocrinology and Metabolism, vol. 95, no. 3, pp. 1404-1411, 2010.

[90] N. N. Pejnovic, J. M. Pantic, I. P. Jovanovic et al., "Galectin3 deficiency accelerates high-fat diet-induced obesity and amplifies inflammation in adipose tissue and pancreatic islets," Diabetes, vol. 62, no. 6, pp. 1932-1944, 2013.

[91] C. Iacobini, L. Amadio, G. Oddi et al., "Role of galectin-3 in diabetic nephropathy," Journal of the American Society of Nephrology, vol. 14, no. 3, pp. S264-S270, 2003.

[92] N. N. Pejnovic, J. M. Pantic, I. P. Jovanovic et al., "Galectin-3 is a regulator of metaflammation in adipose tissue and pancreatic islets," Adipocyte, vol. 2, no. 4, pp. 266-271, 2013.

[93] M. Teresa Ortega, L. Xie, S. Mora, and S. K. Chapes, "Evaluation of macrophage plasticity in brown and white adipose tissue," Cellular Immunology, vol. 271, no. 1, pp. 124-133, 2011.

[94] R. Novak, S. Dabelic, and J. Dumic, "Galectin-1 and galectin3 expression profiles in classically and alternatively activated human macrophages," Biochimica et Biophysica Acta (BBA)General Subjects, vol. 1820, no. 9, pp. 1383-1390, 2012.

[95] C. Iacobini, S. Menini, C. Ricci et al., "Galectin-3 ablation protects mice from diet-induced NASH: a major scavenging role for galectin-3 in liver," Journal of Hepatology, vol. 54, no. 5, pp. 975-983, 2011.

[96] K. Nomoto, K. Tsuneyama, H. O. Abdel Aziz et al., "Disrupted galectin-3 causes non-alcoholic fatty liver disease in male mice," Journal of Pathology, vol. 210, no. 4, pp. 469-477, 2006.

[97] P. G. Traber and E. Zomer, "Therapy of experimental NASH and fibrosis with galectin inhibitors," PLOS ONE, vol. 8, no. 12, Article ID e83481, 2013.

[98] P. Li, S. Liu, M. Lu et al., "Hematopoietic-derived galectin-3 causes cellular and systemic insulin resistance," Cell, vol. 167, no. 4, pp. 973-984.e12, 2016.

[99] C. Eckert, N. Klein, M. Kornek, and V. Lukacs-Kornek, “The complex myeloid network of the liver with diverse functional capacity at steady state and in inflammation," Frontiers in Immunology, vol. 6, article 179, 2015.

[100] D. Hashimoto, A. Chow, C. Noizat et al., "Tissue-resident macrophages self-maintain locally throughout adult life with minimal contribution from circulating monocytes," Immunity, vol. 38, no. 4, pp. 792-804, 2013.

[101] M. Kinoshita, T. Uchida, A. Sato et al., "Characterization of two F4/80-positive Kupffer cell subsets by their function and phenotype in mice," Journal of Hepatology, vol. 53, no. 5, pp. 903-910, 2010.

[102] M. H. Sieweke and J. E. Allen, "Beyond stem cells: self-renewal of differentiated macrophages," Science, vol. 342, no. 6161, Article ID 1242974, 2013.

[103] G. Lanzoni, V. Cardinale, and G. Carpino, "The hepatic, biliary, and pancreatic network of stem/progenitor cell niches in humans: a new reference frame for disease and regeneration," Hepatology, vol. 64, no. 1, pp. 277-286, 2015.

[104] G. Carpino, A. Renzi, A. Franchitto et al., "Stem/progenitor cell niches involved in hepatic and biliary regeneration," Stem Cells International, vol. 2016, Article ID 3658013, 12 pages, 2016.

[105] M. J. Williams, A. D. Clouston, and S. J. Forbes, "Links between hepatic fibrosis, ductular reaction, and progenitor cell expansion," Gastroenterology, vol. 146, no. 2, pp. 349-356, 2014.

[106] B. Spee, G. Carpino, B. A. Schotanus et al., "Characterisation of the liver progenitor cell niche in liver diseases: potential involvement of Wnt and Notch signalling," Gut, vol. 59, no. 2, pp. 247-257, 2010.
[107] S. Sakaguchi, S. Takahashi, T. Sasaki, T. Kumagai, and K. Nagata, "Progression of alcoholic and non-alcoholic steatohepatitis: common metabolic aspects of innate immune system and oxidative stress," Drug Metabolism and Pharmacokinetics, vol. 26, no. 1, pp. 30-46, 2011.

[108] . Wan J, M. Benkdane, and F. Teixeira-Clerc, M2 Kupffer cells promote M1 Kupffer cell apoptosis: A protective mechanism against alcoholic and non-alcoholic fatty liver disease. Hepatology, 57, 141-49, 2012.

[109] W. Huang, A. Metlakunta, N. Dedousis et al., "Depletion of liver kupffer cells prevents the development of diet-induced hepatic steatosis and insulin resistance," Diabetes, vol. 59, no. 2, pp. 347$357,2010$.

[110] N. Lanthier, O. Molendi-Coste, P. D. Cani, N. van Rooijen, Y. Horsmans, and I. A. Leclercq, "Kupffer cell depletion prevents but has no therapeutic effect on metabolic and inflammatory changes induced by a high-fat diet," The FASEB Journal, vol. 25, no. 12, pp. 4301-4311, 2011.

[111] E. Seki and R. F. Schwabe, "Hepatic inflammation and fibrosis: functional links and key pathways," Hepatology, vol. 61, no. 3, pp. 1066-1079, 2015.

[112] S. M. A. Walenbergh, T. Houben, T. Hendrikx et al., "Weekly treatment of 2-hydroxypropyl- $\beta$-cyclodextrin improves intracellular cholesterol levels in LDL receptor knockout mice," International Journal of Molecular Sciences, vol. 16, no. 9, pp. 21056-21069, 2015.

[113] A. Leroux, G. Ferrere, V. Godie et al., "Toxic lipids stored by Kupffer cells correlates with their pro-inflammatory phenotype at an early stage of steatohepatitis," Journal of Hepatology, vol. 57, no. 1, pp. 141-149, 2012.

[114] A. Parlesak, C. Schäfer, T. Schütz, J. C. Bode, and C. Bode, "Increased intestinal permeability to macromolecules and endotoxemia in patients with chronic alcohol abuse in different stages of alcohol-induced liver disease," Journal of Hepatology, vol. 32, no. 5, pp. 742-747, 2000.

[115] C. A. Rivera, P. Adegboyega, N. van Rooijen, A. Tagalicud, M. Allman, and M. Wallace, "Toll-like receptor-4 signaling and Kupffer cells play pivotal roles in the pathogenesis of nonalcoholic steatohepatitis," Journal of Hepatology, vol. 47, no. 4, pp. 571-579, 2007.

[116] S. Chatterjee, D. Ganini, E. J. Tokar et al., "Leptin is key to peroxynitrite-mediated oxidative stress and Kupffer cell activation in experimental non-alcoholic steatohepatitis," Journal of Hepatology, vol. 58, no. 4, pp. 778-784, 2013.

[117] L. Scheja and J. Kluwe, "Arginine and NASH—do macrophages deliver the first hit?" Journal of Hepatology, vol. 62, no. 2, pp. 260-261, 2015.

[118] L. A. Navarro, A. Wree, D. Povero et al., "Arginase 2 deficiency results in spontaneous steatohepatitis: a novel link between innate immune activation and hepatic de novo lipogenesis," Journal of Hepatology, vol. 62, no. 2, pp. 412-420, 2015.

[119] D. Zhou, C. Huang, Z. Lin et al., "Macrophage polarization and function with emphasis on the evolving roles of coordinated regulation of cellular signaling pathways," Cellular Signalling, vol. 26, no. 2, pp. 192-197, 2014.

[120] D. M. Van Rooyen, L. T. Gan, M. M. Yeh et al., "Pharmacological cholesterol lowering reverses fibrotic NASH in obese, diabetic mice with metabolic syndrome," Journal of Hepatology, vol. 59, no. 1, pp. 144-152, 2013. 
[121] M. Itoh, H. Kato, T. Suganami et al., "Hepatic crown-like structure: a unique histological feature in non-alcoholic steatohepatitis in mice and humans," PLoS ONE, vol. 8, no. 12, Article ID e82163, 2013.

[122] G. N. Ioannou, D. M. Van Rooyen, C. Savard et al., "Cholesterollowering drugs cause dissolution of cholesterol crystals and disperse Kupffer cell crown-like structures during resolution of NASH," Journal of Lipid Research, vol. 56, no. 2, pp. 277-285, 2015.

[123] H. Tilg and A. R. Moschen, "IL-1 cytokine family members and NAFLD: neglected in metabolic liver inflammation," Journal of Hepatology, vol. 55, no. 5, pp. 960-962, 2011.

[124] R. Stienstra, F. Saudale, C. Duval et al., "Kupffer cells promote hepatic steatosis via interleukin-1 $\beta$-dependent suppression of peroxisome proliferator-activated receptor $\alpha$ activity," Hepatology, vol. 51, no. 2, pp. 511-522, 2010.

[125] S. Olteanu, M. Kandel-Kfir, A. Shaish et al., "Lack of interleukin$1 \alpha$ in Kupffer cells attenuates liver inflammation and expression of inflammatory cytokines in hypercholesterolaemic mice," Digestive and Liver Disease, vol. 46, no. 5, pp. 433-439, 2014.

[126] K. Miura, L. Yang, N. van Rooijen, H. Ohnishi, and E. Seki, "Hepatic recruitment of macrophages promotes nonalcoholic steatohepatitis through CCR2," American Journal of Physiology-Gastrointestinal and Liver Physiology, vol. 302, no. 11, pp. G1310-G1321, 2012.

[127] C. Brenner, L. Galluzzi, O. Kepp, and G. Kroemer, "Decoding cell death signals in liver inflammation," Journal of Hepatology, vol. 59, no. 3, pp. 583-594, 2013.

[128] A. Canbay, A. E. Feldstein, H. Higuchi et al., "Kupffer cell engulfment of apoptotic bodies stimulates death ligand and cytokine expression," Hepatology, vol. 38, no. 5, pp. 1188-1198, 2003.

[129] L. Idrissova, H. Malhi, N. W. Werneburg et al., "TRAIL receptor deletion in mice suppresses the inflammation of nutrient excess," Journal of Hepatology, vol. 62, no. 5, pp. 1156-1163, 2015.

[130] T. A. Wynn and T. R. Ramalingam, "Mechanisms of fibrosis: therapeutic translation for fibrotic disease," Nature Medicine, vol. 18, pp. 1028-1040, 2012.

[131] G. Carpino, A. Renzi, P. Onori, and E. Gaudio, "Role of hepatic progenitor cells in nonalcoholic fatty liver disease development: cellular cross-talks and molecular networks," International Journal of Molecular Sciences, vol. 14, no. 10, pp. 20112-20130, 2013.

[132] S. Carotti, S. Morini, S. G. Corradini et al., "Glial fibrillary acidic protein as an early marker of hepatic stellate cell activation in chronic and posttransplant recurrent hepatitis C," Liver Transplantation, vol. 14, no. 6, pp. 806-814, 2008.

[133] J.-P. Pradere, J. Kluwe, S. De Minicis et al., "Hepatic macrophages but not dendritic cells contribute to liver fibrosis by promoting the survival of activated hepatic stellate cells in mice," Hepatology, vol. 58, no. 4, pp. 1461-1473, 2013.

[134] A. Pellicoro, P. Ramachandran, J. P. Iredale, and J. A. Fallowfield, "Liver fibrosis and repair: immune regulation of wound healing in a solid organ," Nature Reviews Immunology, vol. 14, no. 3, pp. 181-194, 2014.

[135] L. Boulter, W.-Y. Lu, and S. J. Forbes, "Differentiation of progenitors in the liver: a matter of local choice," Journal of Clinical Investigation, vol. 123, no. 5, pp. 1867-1873, 2013.

[136] C. Baeck, A. Wehr, K. R. Karlmark et al., "Pharmacological inhibition of the chemokine CCL2 (MCP-1) diminishes liver macrophage infiltration and steatohepatitis in chronic hepatic injury," Gut, vol. 61, no. 3, pp. 416-426, 2012.
[137] R. W. Walker, H. Allayee, A. Inserra et al., "Macrophages and fibrosis in adipose tissue are linked to liver damage and metabolic risk in obese children," Obesity, vol. 22, no. 6, pp. 1512-1519, 2014.

[138] L. K. Weaver, K. A. Hintz-Goldstein, P. A. Pioli et al., "Pivotal advance: activation of cell surface Toll-like receptors causes shedding of the hemoglobin scavenger receptor CD163," Journal of Leukocyte Biology, vol. 80, no. 1, pp. 26-35, 2006.

[139] K. Kazankov, H. J. Møller, A. Lange et al., "The macrophage activation marker SCD163 is associated with changes in NAFLD and metabolic profile during lifestyle intervention in obese children," Pediatric Obesity, vol. 10, no. 3, pp. 226-233, 2015.

[140] V. L. Gadd, R. Skoien, E. E. Powell et al., "The portal inflammatory infiltrate and ductular reaction in human nonalcoholic fatty liver disease," Hepatology, vol. 59, no. 4, pp. 1393-1405, 2014.

[141] V. Nobili, A. Alisi, R. Cutrera et al., "Altered gut-liver axis and hepatic adiponectin expression in OSAS: novel mediators of liver injury in paediatric non-alcoholic fatty liver," Thorax, vol. 70, no. 8, pp. 769-781, 2015.

[142] N. Lanthier, "Targeting Kupffer cells in non-alcoholic fatty liver disease/non-alcoholic steatohepatitis: why and how?" World Journal of Hepatology, vol. 7, no. 19, pp. 2184-2188, 2015.

[143] E. Lefebvre, G. Moyle, R. Reshef et al., "Antifibrotic effects of the dual CCR2/CCR5 antagonist cenicriviroc in animal models of liver and kidney fibrosis," PLOS ONE, vol. 11, no. 6, Article ID e0158156, 2016.

[144] S. Friedman, A. Sanyal, Z. Goodman et al., "Efficacy and safety study of cenicriviroc for the treatment of non-alcoholic steatohepatitis in adult subjects with liver fibrosis: CENTAUR Phase 2b study design," Contemporary Clinical Trials, vol. 47, pp. 356-365, 2016.

[145] A. Ichimura, A. Hirasawa, O. Poulain-Godefroy et al., "Dysfunction of lipid sensor GPR120 leads to obesity in both mouse and human," Nature, vol. 483, no. 7389, pp. 350-354, 2012.

[146] S. Talukdar, J. M. Olefsky, and O. Osborn, "Targeting GPR120 and other fatty acid-sensing GPCRs ameliorates insulin resistance and inflammatory diseases," Trends in Pharmacological Sciences, vol. 32, no. 9, pp. 543-550, 2011.

[147] V. Nobili, G. Carpino, A. Alisi et al., "Role of docosahexaenoic acid treatment in improving liver histology in pediatric nonalcoholic fatty liver disease," PLoS ONE, vol. 9, no. 2, Article ID e88005, 2014.

[148] V. Nobili, A. Alisi, C. Della Corte et al., "Docosahexaenoic acid for the treatment of fatty liver: randomised controlled trial in children," Nutrition, Metabolism and Cardiovascular Diseases, vol. 23, no. 11, pp. 1066-1070, 2013.

[149] V. Nobili, G. Bedogni, A. Alisi et al., "Docosahexaenoic acid supplementation decreases liver fat content in children with non-alcoholic fatty liver disease: double-blind randomised controlled clinical trial," Archives of Disease in Childhood, vol. 96, no. 4, pp. 350-353, 2011.

[150] A. Wree, L. Broderick, A. Canbay, H. M. Hoffman, and A. E. Feldstein, "From NAFLD to NASH to cirrhosis-new insights into disease mechanisms," Nature Reviews Gastroenterology and Hepatology, vol. 10, no. 11, pp. 627-636, 2013.

[151] G. Carpino, V. Nobili, A. Renzi et al., "Macrophage activation in pediatric nonalcoholic fatty liver disease (NAFLD) correlates with hepatic progenitor cell response via Wnt3a pathway," PLoS ONE, vol. 11, no. 6, Article ID e0157246, 2016.

[152] I. Jeftic, N. Jovicic, J. Pantic, N. Arsenijevic, M. L. Lukic, and N. Pejnovic, "Galectin-3 ablation enhances liver steatosis, but 
attenuates inflammation and IL-33-dependent fibrosis in obesogenic mouse model of nonalcoholic steatohepatitis," Molecular Medicine, vol. 21, pp. 453-465, 2015.

[153] S. A. Harrison, S. R. Marri, N. Chalasani et al., "Randomised clinical study: GR-MD-02, a galectin-3 inhibitor, vs. placebo in patients having non-alcoholic steatohepatitis with advanced fibrosis," Alimentary Pharmacology \& Therapeutics, vol. 44, no. 11-12, pp. 1183-1198, 2016.

[154] S. R. Rittling, “Osteopontin in macrophage function," Expert Reviews in Molecular Medicine, vol. 13, article e15, 2011.

[155] J. D. Coombes, M. Swiderska-Syn, L. Dollé et al., “Osteopontin neutralisation abrogates the liver progenitor cell response and fibrogenesis in mice," Gut, vol. 64, no. 7, pp. 1120-1131, 2015.

[156] H. Kwon, K. Song, C. Han et al., "Inhibition of hedgehog signaling ameliorates hepatic inflammation in mice with nonalcoholic fatty liver disease," Hepatology, vol. 63, no. 4, pp. 1155-1169, 2016. 


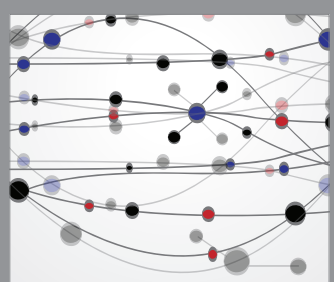

The Scientific World Journal
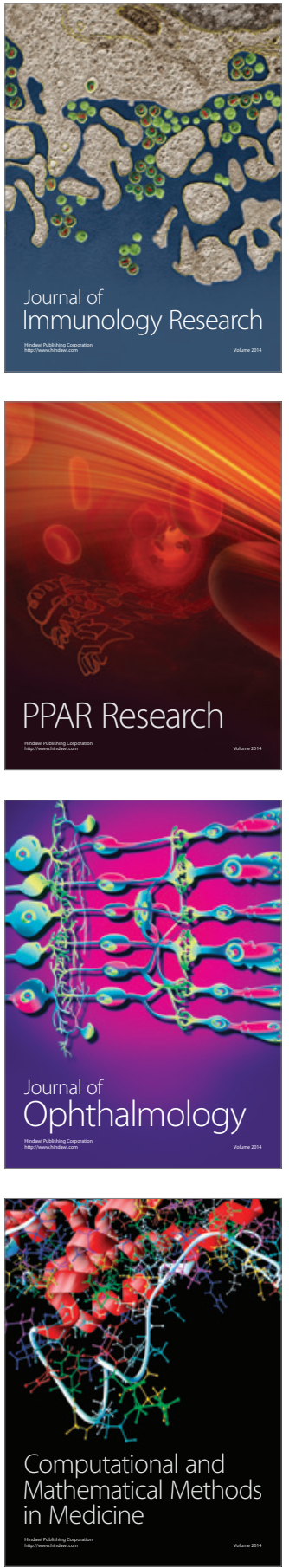

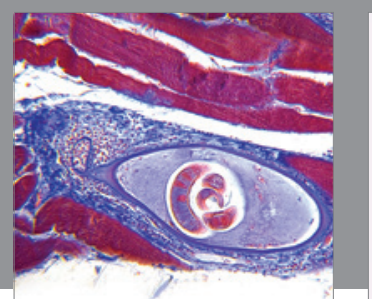

Gastroenterology Research and Practice
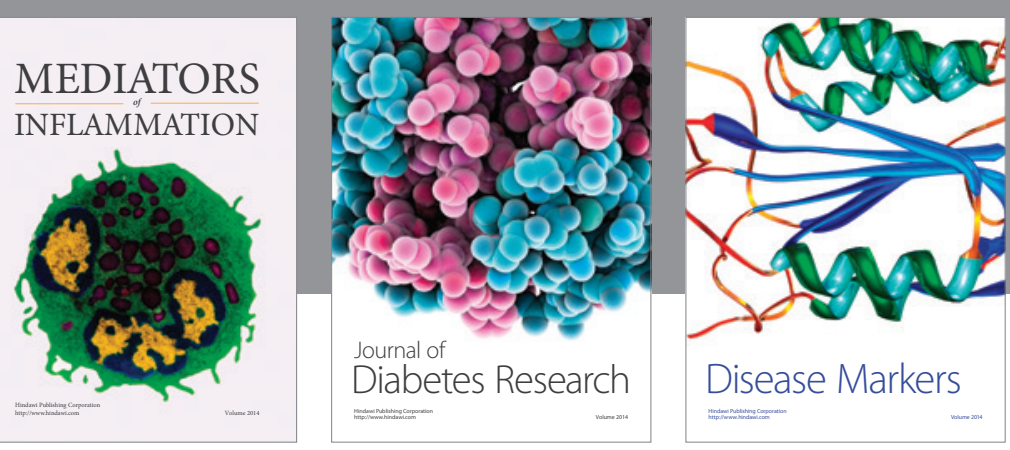

Disease Markers

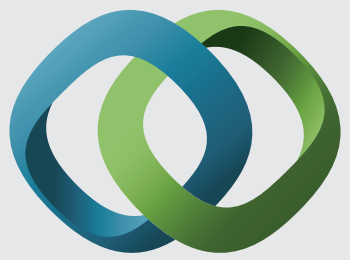

\section{Hindawi}

Submit your manuscripts at

https://www.hindawi.com
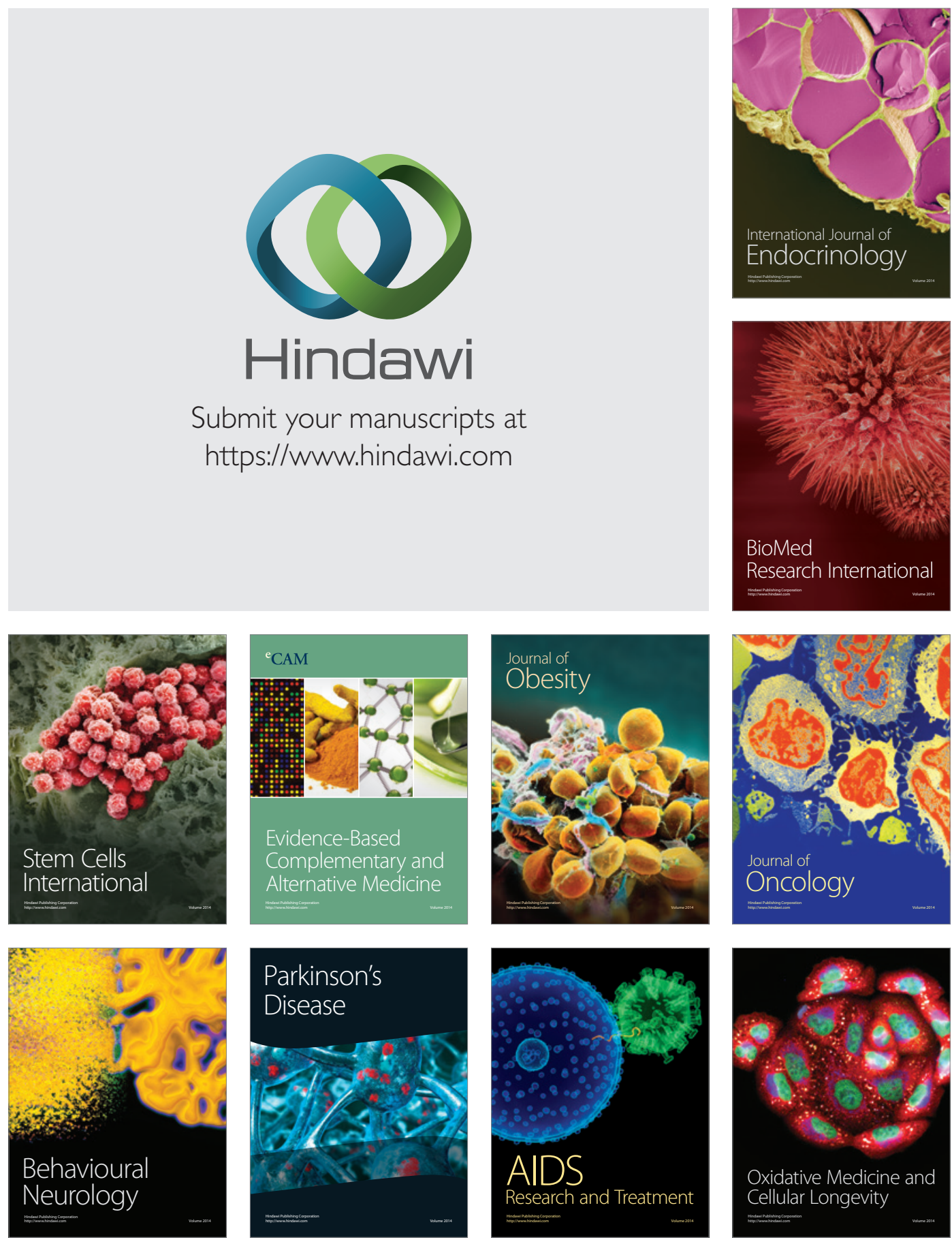